\title{
EFFECT OF EXOGENOUS PROTEASES ON THE SPERMIOGRAM AND MICROSCOPIC AND MACROSCOPIC CHARACTERISTICS OF BOAR EJACULATE
}

\author{
ŁUKASZ ZIELONKA, WŁODZIMIERZ PRZEWOSKI ${ }^{1}$, MAGDALENA GAJĘCKA, \\ EWA JAKIMIUK, AND MACIEJ GAJĘCKI
}

\author{
Department of Veterinary Prevention and Feed Hygiene, \\ Faculty of Veterinary Medicine, \\ University of Warmia and Mazury in Olsztyn, 10-718 Olsztyn, Poland \\ ${ }^{1}$ Provincial Veterinary Inspection in Gdansk, 80-958 Gdansk, Poland \\ lukasz.zielonka@uwm.edu.pl
}

Received: March 25, 2013

Accepted: June 7, 2013

\begin{abstract}
A growing interest in enzymatic growth promoters prompted the authors of the study to investigate the effects of a stimulating enzymatic complex on ejaculate characteristics of boars. The enzymatic complex comprising five proteases (proteinases - endopeptidases) and two peptidases (exopeptidases) was obtained by fermentation from Streptomyces fradiae. This complex was added to boar diets for 3 months at the initial doses of 90 (group E1) and 120 (group E2) g/ton of feed in the first week, followed by 40 and $60 \mathrm{~g} / \mathrm{ton}$, respectively, in the following weeks. Evaluation was based on the assessment of key ejaculate characteristics (volume, sperm concentration, total sperm count, primary and secondary sperm defects). The enzymatic complex improved the microscopic and macroscopic characteristics of boar ejaculate by increasing sperm concentrations and total sperm counts, and decreasing the volume of the analysed ejaculates without significant changes in the spermiograms of primary and secondary defects.
\end{abstract}

Key words: boars, proteolytic enzymes, spermiogram, ejaculate.

The reproductive activity of boars is affected by the quality and health benefits of feed (6), especially in terms of digestion and absorption of feed in the gastrointestinal tract. The latter factors are subject to constant adaptive changes. Stimulation or inhibition of exocrine pancreas secretion is a mechanism of situational adaptation (8). All organs of the gastrointestinal system, including the pancreas, are controlled by the nervous and hormonal systems, and they are affected by the quantity, quality, structure, and health attributes of the administered diets, as well as the applied nutritional regime. The characteristics of feed are highly variable due to environmental factors, and animals are often required to adapt to environmental changes on a daily basis. Under the intensive production conditions, the level of nutrition often exceeds the maintenance requirements of animals; therefore, a great attention needs to be paid to the functioning of their gastrointestinal system. Positive effect of dietary supplementation with vitamin $\mathrm{E}$ and selenium, and positive effects of unsaturated fatty acids on semen parameters are known (10). A high dietary intake of energy and all nutrient components is also important. Following the ban of the use of antibiotic growth promoters, the importance of the positive effect of feed additives on metabolism and production parameters increases.

The above arguments support the use of exogenous proteases, which, in theory, should lower cholecystokinin concentrations (12), blocking the satiation response and leading to an increase of appetite. This, however, should stimulate gastric activity and maximise nutrient absorption in the intestines. This type of stimulatory substances are safe to use because they do not penetrate the body and they affect only the digestive tract (9)

The objective of the study was to evaluate the effects of a stimulating enzymatic complex added to feed on the quality of boar ejaculate.

\section{Material and Methods}

The effectiveness of a stimulating enzymatic complex comprising seven bacterial extracellular proteolytic enzymes: five proteases (proteinases endopeptidases) and two peptidases (exopeptidases) obtained from Streptomyces fradiae in the process of fermentation was evaluated. The complex was supplied by Gist-Brocades (France). The complex was composed of type II proteases with molecular mass of 
approximately 18,000, an isoelectric point of approximately 9.0, and electrophoresis at $\mathrm{pH} 8.0$ (up to $40 \%$ total activity); type III proteases with molecular mass of approximately 14,000 , and the remaining indicators identical to the above (up to $30 \%$ total activity); type IV proteases with molecular mass of approximately 16,500 and the remaining indicators identical to the above (up to $30 \%$ total activity). This classification was based on the procedure of isolating and purifying of particular enzymes, and the enzyme (complex) numbers correspond to the numbers of chromatographic fractions (3).

A total of 37 crossbred boars from the Animal Breeding and Insemination Center in Pętkowice (Poland) have been administered the same enzymatic complex for three months in the following doses: experimental group 1 (E1 - 12 boars) $-90 \mathrm{~g} /$ ton of feed in the first $7 \mathrm{~d}$, followed by $40 \mathrm{~g} / \mathrm{kg}$ of feed until the end of the experiment; experimental group 2 (E2 - 12 boars) $-120 \mathrm{~g} /$ ton of feed in the first $7 \mathrm{~d}$, followed by $60 \mathrm{~g} / \mathrm{kg}$ of feed until the end of the experiment (12). The experiment also involved a control group ( $\mathrm{C}-13$ boars). Semen was collected from all boars using the gloved hand technique. The boars were accustomed to the procedure, which was carried out once or twice per week by the same person.

Density of raw semen was estimated using a colorimeter and then diluted for further use with a commercial extender. The number of spermatozoa in diluted semen was determined in duplicate using a Makler counting chamber and phase-contrast microscope. Stained semen smears were prepared by mixing diluted semen with nigrosin-eosin stains to evaluate sperm morphology and viability or with Giemsa stain to evaluate acrosome structures.

Table 1

Spermiogram - primary defects $(\%)(\mathrm{x}, \mathrm{s})$

\begin{tabular}{|c|c|c|c|c|c|c|}
\hline \multirow{3}{*}{ Defect } & \multicolumn{3}{|c|}{ Date 1} & \multicolumn{3}{|c|}{ Date 2} \\
\hline & \multicolumn{3}{|c|}{ Group } & \multicolumn{3}{|c|}{ Group } \\
\hline & $\mathrm{C}$ & E1 & E2 & $\mathrm{C}$ & E1 & E2 \\
\hline \multirow[t]{2}{*}{ Immature sperm } & 0.00 & 0.00 & 0.00 & 0.00 & 0.00 & 0.00 \\
\hline & 0.00 & 0.00 & 0.00 & 0.00 & 0.00 & 0.00 \\
\hline \multirow{2}{*}{ Duplicated sperm } & 0.00 & 0.00 & 0.00 & 0.00 & 0.00 & 0.00 \\
\hline & 0.00 & 0.00 & 0.00 & 0.00 & 0.00 & 0.00 \\
\hline \multirow{2}{*}{ Round head } & 0.00 & 0.00 & 0.00 & 0.00 & 0.00 & 0.00 \\
\hline & 0.00 & 0.00 & 0.00 & 0.00 & 0.00 & 0.00 \\
\hline \multirow{2}{*}{ Headless sperm } & 0.00 & 0.00 & 0.00 & 0.00 & 0.00 & 0.00 \\
\hline & 0.00 & 0.00 & 0.00 & 0.00 & 0.00 & 0.00 \\
\hline \multirow{2}{*}{ Cratered head } & 0.00 & 0.00 & 0.00 & 0.00 & 0.00 & 0.00 \\
\hline & 0.00 & 0.00 & 0.00 & 0.00 & 0.00 & 0.00 \\
\hline \multirow{2}{*}{ Pyriform head } & 0.88 & 1.38 & 1.39 & 1.11 & 1.23 & 1.00 \\
\hline & 0.75 & 0.35 & 0.60 & 0.33 & 0.41 & 0.61 \\
\hline \multirow{2}{*}{ Tapering head } & 0.75 & $1.25 *$ & 1.22 & 1.39 & 1.09 & 1.30 \\
\hline & 0.29 & 0.27 & 0.57 & 0.33 & 0.44 & 0.57 \\
\hline \multirow{2}{*}{ Amorphous sperm } & 1.00 & 1.56 & 1.61 & 1.44 & 1.27 & 2.10 \\
\hline & 0.58 & 0.73 & 1.02 & 0.58 & 0.34 & 1.67 \\
\hline \multirow{2}{*}{ Microcephalic sperm } & 0.13 & 0.25 & 0.33 & 0.11 & 0.14 & 0.10 \\
\hline & 0.25 & 0.27 & 0.66 & 0.22 & 0.23 & 0.22 \\
\hline \multirow{2}{*}{ Loose abnormal head } & 0.25 & 0.25 & 0.00 & 0.06 & 0.23 & 0.20 \\
\hline & 0.29 & 0.27 & 0.00 & 0.17 & 0.26 & 0.27 \\
\hline \multirow{2}{*}{ Corkscrew midpiece } & 0.13 & 0.00 & 0.00 & 0.00 & 0.00 & 0.00 \\
\hline & 0.25 & 0.00 & 0.00 & 0.00 & 0.00 & 0.00 \\
\hline \multirow{2}{*}{$\begin{array}{l}\text { Other midpiece } \\
\text { abnormalities }\end{array}$} & 1.00 & 2.88 & 1.28 & 1.39 & 1.14 & 1.30 \\
\hline & 0.41 & 3.71 & 0.36 & 0.42 & 0.39 & 0.27 \\
\hline \multirow{2}{*}{ Proximal droplet } & 2.88 & 6.56 & 3.72 & 1.67 & 1.91 & 11.4 \\
\hline & 2.84 & 4.78 & 3.36 & 0.68 & 0.80 & 16.21 \\
\hline \multirow{2}{*}{ Pseudo-droplet } & 0.75 & 1.31 & 0.72 & 0.00 & 0.00 & 0.00 \\
\hline & 0.87 & 0.84 & 0.75 & 0.00 & 0.00 & 0.00 \\
\hline \multirow{2}{*}{ Dag defect } & 0.63 & 1.81 & 0.88 & 0.89 & 1.05 & 1.50 \\
\hline & 0.25 & 1.36 & 0.35 & 0.33 & 0.47 & 1.00 \\
\hline \multirow{2}{*}{ Total primary defects } & 8.38 & 14.69 & 11.39 & 9.06 & 8.41 & 19.00 \\
\hline & 5.76 & 7.30 & 6.66 & 2.24 & 1.93 & 17.52 \\
\hline
\end{tabular}

* - P $\leq 0.05 ; \mathrm{C}$ control group, E1, E2 - experimental groups 
Boar ejaculates were evaluated on the first and on the last day of the experiment (ejaculate volume, sperm concentration, total sperm count, primary and secondary sperm defects).

To evaluate the significance of the experimental factors, the obtained results were validated statistically with the use of STATISTICA (7) PL and WINSTAT applications, by an analysis of variance and significance tests for dependent samples (within the experimental group) and independent samples (between the experimental groups).

\section{Results}

The spermiogram of primary defects noted on date 2 (Table 1) shows a statistically significant difference in tapering head values between groups $\mathrm{C}$ and E1 $(0.50 \%)$. A statistical analysis of secondary defects on date 2 (Table 2) revealed statistically significant differences in narrow head $(0.43 \%)$ and coiled tail $(0.67 \%)$ values between groups E1 and E2.

The results of statistical analyses of microscopic and macroscopic characteristics of boar ejaculate are presented in Table 3. Statistically significant differences were determined on date 1 between groups E1 and E2 in ejaculate volume values (difference of $43.23 \mathrm{~mL}$ ). On date 1, highly significant differences were noted between groups $\mathrm{C}$ and $\mathrm{E} 1$ in regard to sperm concentrations (difference of $101.00 \mathrm{x}$ $10^{6} / \mathrm{mL}$ ) and total sperm counts (difference of $32.82 \mathrm{x}$ $10^{9}$ ). On date 1 , highly significant differences were also noted between groups $\mathrm{C}$ and E2 in ejaculate volume (difference of $67.35 \mathrm{~mL}$, sperm concentrations (difference of $100.27 \times 10^{6} / \mathrm{mL}$ ), and total sperm counts (difference of $32.59 \times 10^{9}$ ).

Table 2

Spermiogram - secondary defects $(\%)(x, s)$

\begin{tabular}{lcccccc}
\hline \multirow{2}{*}{ Defect } & \multicolumn{3}{c}{ Date 1 } & \multicolumn{3}{c}{ Date 2 } \\
\cline { 2 - 6 } & \multicolumn{3}{c}{ Group } & & \multicolumn{2}{c}{ Group } \\
\cline { 2 - 6 } Narrow head & 1.22 & 1.36 & 1.10 & 1.38 & 1.81 & 1.38 \\
& 0.26 & 0.39 & 0.55 & 0.75 & 0.46 & 0.23 \\
\hline \multirow{2}{*}{ Normal small head } & 0.06 & 0.23 & 0.30 & 0.25 & 0.13 & 0.06 \\
& 0.17 & 0.26 & 0.45 & 0.29 & 0.23 & 0.17 \\
\hline \multirow{2}{*}{ Giant head } & 0.39 & 0.23 & 0.10 & 0.00 & 0.13 & 0.06 \\
& 0.33 & 0.34 & 0.22 & 0.00 & 0.23 & 0.17 \\
\multirow{2}{*}{ Normal loose head } & 1.61 & 1.59 & 1.80 & 1.13 & 1.50 & 1.39 \\
\multirow{2}{*}{ Separated acrosomal membrane } & 0.42 & 0.58 & 0.76 & 0.63 & 0.38 & 0.49 \\
\hline \multirow{2}{*}{ Abaxial head } & 0.00 & 0.00 & 0.00 & 0.00 & 0.00 & 0.00 \\
& 0.00 & 0.00 & 0.00 & 0.00 & 0.00 & 0.00 \\
\hline \multirow{2}{*}{ Distal drop } & 0.89 & 1.09 & 1.30 & 1.00 & 1.69 & 1.28 \\
& 0.22 & 0.30 & 0.57 & 0.71 & 0.46 & 0.62 \\
\multirow{2}{*}{ Bent tail } & 3.44 & 3.68 & 5.90 & 3.63 & 6.69 & 5.17 \\
& 1.36 & 3.88 & 4.95 & 3.35 & 3.01 & 3.52 \\
\hline \multirow{2}{*}{ Coiled tail } & 2.94 & 6.77 & 3.00 & 3.50 & 13.69 & 3.67 \\
& 0.73 & 11.32 & 0.79 & 3.03 & 16.48 & 3.52 \\
\hline \multirow{2}{*}{ Total secondary defects } & 0.83 & 1.32 & 0.90 & 0.88 & 1.56 & 0.89 \\
& 0.25 & 0.72 & 0.42 & 0.75 & 0.78 & 0.49 \\
\hline
\end{tabular}

Symbols as in the Table 1

Table 3

Results of microscopic and macroscopic evaluations of boar ejaculate

\begin{tabular}{|c|c|c|c|c|c|c|}
\hline \multirow{3}{*}{ Parameter } & \multicolumn{3}{|c|}{ Date 1} & \multicolumn{3}{|c|}{ Date 2} \\
\hline & \multicolumn{3}{|c|}{ Group } & \multicolumn{3}{|c|}{ Group } \\
\hline & $\mathrm{C}$ & E1 & E2 & $\mathrm{C}$ & E1 & E2 \\
\hline \multirow{2}{*}{ Ejaculate volume $\mathrm{ml}$} & 199.55 & 223.67 & $266.9 * * \nabla$ & 303.55 & $237.87^{\circ \circ}$ & $250.1 *$ \\
\hline & 12.48 & 41.07 & 40.51 & 46.81 & 10.49 & 54.55 \\
\hline Sperm concentration & 298.73 & $399.73^{\circ 0}$ & $399.0 * *$ & 328.09 & $447.87^{\circ \circ}$ & $444.7 *$ \\
\hline$\times 10^{6} / \mathrm{mL}$ & 21.38 & 91.91 & 41.36 & 89.34 & 17.26 & 107.52 \\
\hline Total sperm count & 62.42 & $95.24^{\circ 0}$ & $95.01 * *$ & 85.39 & $109.69^{\circ \circ}$ & $83.79^{\nabla \nabla}$ \\
\hline X $10^{9}$ & 15.54 & 8.94 & 12.32 & 19.65 & 6.05 & 6.94 \\
\hline
\end{tabular}

$\circ$ - $\mathrm{P} \leq 0.01, *-\mathrm{P} \leq 0.05, * *-\mathrm{P} \leq 0.01, \nabla-\mathrm{P} \leq 0.05, \nabla \nabla-\mathrm{P} \leq 0.01 ; \mathrm{C}-$ control group, E1, E2 - experimental groups 
On date 2 (Table 3), significant differences were observed between groups $\mathrm{C}$ and E2 in ejaculate volume (difference of $53.45 \mathrm{~mL}$ ) and sperm concentrations (difference of $116.61 \times 10^{6} / \mathrm{mL}$ ). On the same date, highly significant differences were noted between groups $\mathrm{C}$ and $\mathrm{E} 1$ in the values of ejaculate volume (difference of $65.68 \mathrm{~mL}$ ), sperm concentrations (difference of $119.78 \times 10^{6} / \mathrm{mL}$ ), and total sperm counts (difference of $24.30 \times 10^{9}$ ). Highly significant differences were reported between groups E1 and E2 with regard to total sperm count values (difference of $25.90 \times 10^{9}$ ).

\section{Discussion}

The presented values of the spermiogram show no general differences on both experimental dates. There were no symptoms suggesting that the tested stimulating enzymatic complex had any effect on the analysed boars, in particular on the spermatogenesis process. A strong correlation exists between animal nutrition and the homeostasis of the body and individual organs (2). All organs of the digestive system, including the pancreas, are subject to nervous and humoral control and local regulation, and they are affected by the quantity, quality, structure, and sanitary standards of the administered diets, as well as by the applied nutritional regime. In the production process, special attention needs to be paid to the functioning of the digestive tract (since the level of nutrition often exceeds the maintenance requirements of animals) and the reproductive systems (due to the need to reproduce). It seems that the above requirements were not fulfilled in the investigated animals.

The extrapolation of the obtained results suggests that the endocrine activity of male gonads, which create a supportive environment for spermatogenesis, is controlled by the nervous and hormonal systems, and the testes (5). In boars, male gonads probably lack internal innervation, and nerve supply reaches only the testicular artery and the pampiniform plexus, implying that the vasomotor control of tunica externa, and septal and intertesticular vessels in the interstitial tissue is not directly affected by the autonomic nervous system. It may seem that autonomic control of the endocrine activity of boar gonads is governed by an identical dependency.

The above indicates that nervous regulation of gonad activity in boars takes place only within the central nervous system. Hormonal control is exercised via the bloodstream, however, this process is slow, and it is determined by various transmitters. The presence of specific membrane and cytoplasmic receptors is also required. To illustrate, the role of FSH and LH (11) is to maintain the activity of Sertoli cells, which leads to the activation of adenylate cyclase and stimulation of cAMP synthesis, and Leydig cells, which stimulates testosterone production after binding to plasma membrane receptors (1). Local regulation mechanisms play a crucial role. The discovery of non-hormonal factors regulating gonad growth and development prompted researchers to re-evaluate the significance of endocrinological control over the reproductive system. These factors act locally on adjacent cells (paracrine regulators) and on cells in the place where they are produced (autocrine regulators).

It can be concluded that central control of gonad activity in boars relies on a functional synergy between the central nervous system and hormonal system (5). Changes in humoral and nervous control of organ functions are often determined by the stability of the digestive tract, and every change affects the entire body. Increased or decreased activity of the stomach and intestines affects the animal's appetite. Increased hormone secretion in the gastrointestinal system is accompanied by similar changes in hormone levels in various brain structures. The fluctuations in hormone levels in the digestive tract and the central nervous system are probably synchronised with the involvement of the autonomic nervous system, which transfers stimuli from the intestines to the central nervous system and back to digestive organs. This synergy between hormones and the nervous system determines mating success in animals $(5,7)$. The results of microscopic and macroscopic evaluations of ejaculate from boars administered per os a stimulating enzymatic complex testify to the above. The studied enzymatic supplement increased sperm concentrations and total sperm counts and decreased ejaculate volume, thus indicating that the intended goal has been achieved. Feeding proteases increased the concentration of spermatozoa, which is similar to results obtained from unsaturated fatty acids supplementation. It seems that this is the result of increasing nutrient availability caused by the action of proteases. Next consequence of increased sperm concentration may be getting a larger number of semen doses, which corresponds with studies on supplementation with omega-3 fatty acids (4).

The results of the experiment support the conclusion that the supplementation of boar diets with a stimulating enzymatic complex improved the microscopic and macroscopic characteristics of boar ejaculate.

\section{References}

1. Avelar G.F., Oliveira C.F.A., Soares J.M., Silva I.J., Dobrinski I., Hess R.A., Franc L.R.: Postnatal somatic cell proliferation and seminiferous tubule maturation in pigs: A non-random event. Theriogenology 2010, 74, 1123.

2. Barej W.: Disorders of the digestive system in animals versus its cyclical functions. Med Weter 1997, 53, 560565.

3. Cabaleiro D.R., Rodríguez-Couto S., Sanromán A., Longo M.A.: Comparison between the protease production ability of ligninolytic fungi cultivated in solid state media. Process Biochem 2002, 37, 1017-1023.

4. Estiene M.J., Harper A.F., Crawford R.J.: Dietary supplementation with source of omega-3 fatty acids increases sperm number and duration of ejaculation in boars. Theriogenology 2008, 70, 70-76.

5. Hemsworth P.H., Tilbrook A.J.: Sexual behavior of male pigs. Horm Behav 2007, 52, 39-44.

6. Hossain M.S., Tareq K.M.A., Hammano K.I., Tsujii H.: Effect of fatty acids on boar sperm motility, viability, and 
acrosome reaction. Biology Reprod Med Biol 2007, 6, 235-239.

7. Jakobsen K., Hedemann M.S.: Studies on exocrine pancreatic secretion in pigs and its possible role in feed formulation and management. Proceedings of XXXI Scientific Session, KNZ-PAN - Fizjologiczne podstawy żywienia zwierząt i ich praktyczne implikacje”, Wroclaw, Poland 2002, p. 73.

8. Kung J.W., Brown A., Kruskal J.B., Goldsmith J.D., Pedrosa I.: Heterotopic pancreas: typical and atypical imaging findings. Clin Radiol 2010, 65, 403-407.

9. Pariza M.W., Cook M.: Determining the safety of enzymes used in animal feed. Regul Toxicol Pharmacol 2010, 56, 332-342.

10. Rooke J.A., Shao C.C., Speake B.K.: Effects of feeding tuna oil on the lipid composition of pig spermatozoa and in vitro characteristics of semen. Reproduction 2001, 121, 315-322.

11. Wagner A., Claus R.: The effects of postnatal FSH substitution on Sertoli cell number and the sperm production capacity of the adult boar. Anim Reprod Sci 2009, 110, 269-282.

12. Valette B.P., Malouin H., Corring T., Savoie L., Gueugneau A.M., Berot S.: Effects of diets containing casein and rapeseed on enzyme secretion from the exocrine pancreas in the pig. Br. J. Nutr. 1992, 67, 215 222.

13. Weiss F.U., Halangk W., Lerch M.M.: New advances in pancreatic cell physiology and pathophysiology. Best Pract Res Clin Gastroenterol 2008, 22, 3-15. 